\title{
Healthy Living for Elders: Use Your Medicines Safely! ${ }^{1}$
}

Paulina Wittkowsky ${ }^{2}$

Q

Medicines can help us feel better. But they can also harm us if they are not used correctly. To use your medicines safely, keep in mind the following tips.

\section{Make sure your doctor and pharmacist} always know all the medicines you are taking.

This includes prescription and over-the-counter medicines, herbal products, and vitamin supplements. Also, remind them about any drug allergies or reactions you have had to

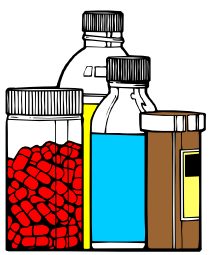
medicines in the past.

\section{Fill all of your prescriptions at the same pharmacy.}

That way, all of your prescription medications will be on your record. Your pharmacist will be able to alert you and your physician of possible problems. Let your pharmacist know if your doctor has told you to stop taking any of your medicines, so it can be noted on your record.

\section{Make sure you can read the medicine} label and understand the directions.

Ask the pharmacist to use large type on your prescription medicine if it is hard to read. Read the label on over-the-counter medicines too.

\section{Keep a record of all the medicines you take.}

Keep a copy of your record in your medicine cabinet and carry one with you. Write down:

- the name of the medicine

- the reason why you take it

- when you take it

- how much to take

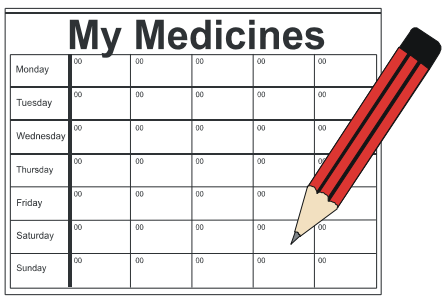

- how long you need to take it

- if it has side effects (like sleepiness or constipation)

1. This document, FCS8594-Eng, is one in a series of the Department of Family, Youth and Community Sciences, Florida Cooperative Extension Service, Institute of Food and Agricultural Sciences, University of Florida, Gainesville, FL 32611. Publication date: March 2004. This leaflet was developed with funding from the Florida Department of Elder Affairs in partnership with state, county, and local agencies. Please visit the EDIS Web site at http://edis.ufl.edu.

2. Paulina Wittkowsky, MS, RD, former education assistant, Department of Family, Youth and Community Sciences, Institute of Food and Agricultural Sciences, University of Florida, Gainesville, FL 32611. Reviewed by Linda B. Bobroff, PhD, RD, LD/N, professor, University of Florida 


\section{Call your doctor right away if you have any problem with your medicines.}

If you are worried that a drug might be doing more harm than good, talk with your doctor. He or she may be able to change your medicine to one that will work better.

\section{Check the expiration date on} medicine bottles.

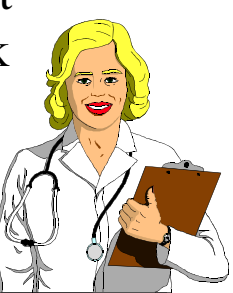

Throw them away if they have passed this date. Ask your doctor if you need a new prescription.

\section{Ask your doctor or pharmacist if you} should take your medicines with or without food.

Certain foods and beverages should be avoided when taking some medicines. Sometimes it is better to take medicine with food to help avoid stomach irritation.

\section{Do not take more or less than} the prescribed amount of any drug.

Your doctor knows what dose is right for you. If you think you should be taking more or less than the recommended amount, talk to your doctor.
Do not drink alcohol when you take your medicines.

Some drugs may not work well or may make you sick if taken with alcohol. Ask your doctor if alcohol can affect the medicines you are taking.

\section{Never take someone else's prescription medicine.}

Medicine prescribed by a doctor is not meant to be shared. It may work for one person, but be dangerous for someone else.

If you have any questions about your medicines, ask your doctor or pharmacist! You need to have information about your health and medicines, in language you can understand.

To learn more about using medicines safely:

- Call the Food and Drug Administration through its toll-free number, 1-888463-6332, or visit this web site: www.fda.gov

- Contact the AARP Pharmacy Service at 1-800-456-2277 or visit this website: www.aarppharmacy.com

Visit the American Pharmaceutical Association's website at: www.pharmacyandyou.org 